\title{
SAMPLE SIZE FOR COMPARISON OF PROPORTIONS
}

\author{
AKIRA SAKUMA \\ Defrartment of Pharmacology, Institute for Cardinascular Diseases, School of Medicine, \\ Tokyo Medical and Dental University, Bunkyo-ku, Tokyo
}

Reccived for publication June 21, 1965

Statistical sample selected from the population under consideration is used to make a decision concerning the null hypothesis. Previous to the experiment, the minimum sample size is determined from $O C$ curvc or power funciton when the null and alternative hypotheses as well as the significance level and power of the test have been set up.

Two sets of OC curves for comparison of two proportions, one- and two-tailed tests (Fig. 1A and $\mathbf{B}$ ), are prepared with the use of arcsine transformation for binomial distribution (1).

The difference which one would like to detect between two proportions, $\mathbf{P}_{\mathrm{H}}$ and $\mathbf{P}_{\mathrm{L}}$, when expressed as io in radian, holds an approximate relation

$$
\delta=\sin ^{-1} \mathrm{P}_{\mathrm{H}}^{1 / 2}-\sin ^{-1} \mathrm{P}_{\mathrm{L}^{1 / 2}}=(2 N)^{-1 / 2}\left(\mathrm{z}_{\alpha}-\mathrm{z}_{\beta}\right)
$$

where $\mathrm{z}_{x}$ and $\mathrm{z}_{\beta}$ are the normal deviates corresponding to the significance level $\alpha$ (type I error) and to the probability $\beta$ of failure to reject the false null hypothesis and to accept the true alternative hypothesis (type II crror), and $\mathrm{N}$ is the sample size of each group. The expression is converted into $\delta$ in degree in order to compute the curves

$$
\delta=\theta_{\mathrm{H}}-\theta_{\mathrm{L}}=40.514(\mathrm{~N})^{-1 / 2}\left(\mathrm{z}_{\alpha}+\mathrm{z}_{\beta}\right)
$$

This approximation gives a slightly steeper curve than it should be when $\mathrm{N}$ is small, say, less than 20.

The test for the null hypothesis is carried out on the basis of the fact that the random variable

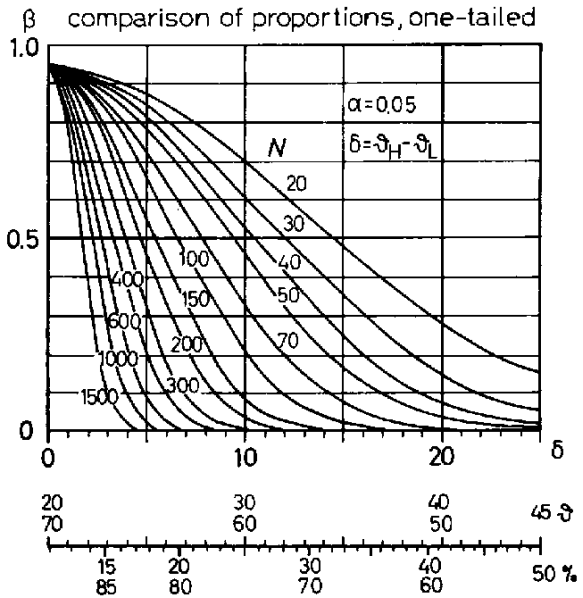

A

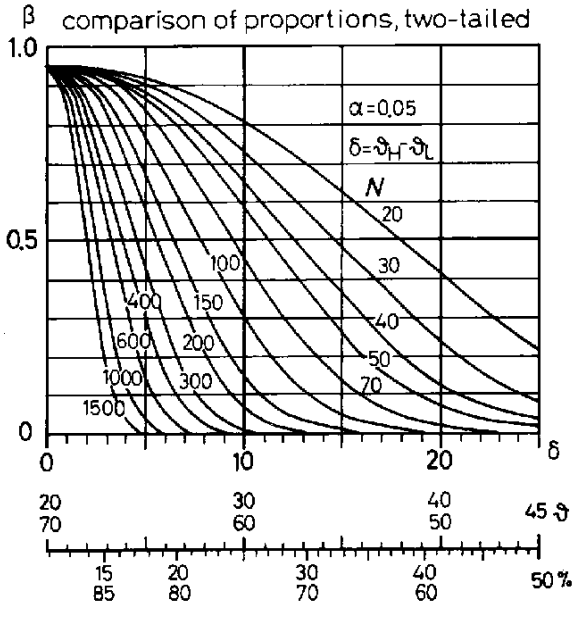

B

FIG. IA. OC curves for one-tailed test.

B. OC curves for two-tailed test. 


$$
\mathrm{z}_{\mathrm{C}}-\left(\theta_{\mathrm{II}} \cdots \theta_{\mathrm{L}}\right)(\mathrm{N})^{1 / 2} / 40.514
$$

approximately has the standardized normal distribution under the null hypothesis that the two proportions are equal.

For the comparison of a proportion $(\theta)$ with a given standard proportion $\left(\theta_{\mathrm{S}}\right)$, the same charts are used for the determination of sample size $\mathrm{N}_{0}$, by putting $\mathrm{N}_{0}=\mathrm{N} / 2$. The statistic in this case is

$$
z_{\mathrm{C}}=\left(D-\theta_{\mathrm{S}}\right)\left(\mathrm{N}_{\mathrm{O}}\right)^{\frac{1}{1 / 2} / 28.648}
$$

Example : Placebo effect has been assumed to be observed in $30 \%$ of the patients. If a new drug has a true effective rate as high as $60 \%$ and if one would like to obtain a significant result with $90 \%$ probability $(\hat{\beta}-1-0.9)$, how many patients should be needed? Since the investigator is interested in whether or not the new drug is superior to the placebo, the chart to be used is for one-tailed test (Fig. 1A). In the transformation scale at the bottom, the difference in degree to be detected is $\delta \div 50.8-33.2=17.6$, the total length from $30 \%$ to $50 \%$ and $50 \%$ to $60 \%$. Entering the chart with $\beta=0.1$ and $\delta=17.6$, one will find $N:-46$. Thus the minimum sample size of each group, control and treated, will be 46 , namely, 92 in all. If one fixed the control rate, he needs 23 patients.

\title{
REFERENCE
}

1) BARTIEIT, M.S. : Biometrics 3, 39 (1947)

\section{EFFEGT OF MUSCLE REFLAXANTS ON THE STRAUB TAIL PHENOMENON}

\author{
R.C. SRIMAL, K.D. JAITLY* AND K.P. BHARGAVA \\ Department of Pharmacology and Therapeutics, K.G. Medical College, \\ Lucknow University, Lucknow, India
}

Received for publication June 30, 1965

The pcculiar effect of morphine in mice, causing their tail to go up into a condition of catatonic rigidity, was first described by Straub (1). This phenomenon has been ascribed to spasm of the anal and vesical sphincters $(2,3)$. Heinekamp (4) ascribed the Straub phenomenon to stimulation of the spinal cord. Gaddum (5) has suggested that the phenomenon is due to a spasm of the vesical and anal sphincters resulting from spinal stimulation. Bilbey et al. (6) showed that the erection of the tail was due to contraction of the sacro-coccygeus muscle. They further showed that the lumbosacral cord (with its peripheral nervous outflow) and the dorsal sacro-coccygcus muscle must be intact for eliciting this reaction. Since the phenomenon appeared to involve both central and peripheral components of the nervous system we thought it worthwhile to study the effects of different central and peripheral muscle relaxants on this phenomenon in order to evaluate the relative importance of the two components in its causation. In this study, the Straub reaction hes been found to be a reliable test object for differentiating contral muscle relaxants from the peripherally acting ones.

White mice of either sex weighing $14-35 \mathrm{~g}$ were employed in the study. The Straub reaction was induced by injecting subcutaneously dihydroxycodeinone pectinate (Proladone, Crookes, $10 \mathrm{mg} / \mathrm{kg}$ ). A batch of 10 micc was employed for each drug tested. The drugs were injected intrapcritoneally

* Present address : Department of Pharmacology, Guy's Hospital Medical School, London, England. 